\title{
GHK and DNA: Resetting the Human Genome to Health
}

\author{
Loren Pickart, Jessica Michelle Vasquez-Soltero, and Anna Margolina
}

Skin Biology, Research \& Development Department, 4122 Factoria Boulevard SE, Suite No. 200, Bellevue, WA 98006, USA

Correspondence should be addressed to Loren Pickart; lorenpickart@skinbiology.com

Received 8 July 2014; Accepted 27 August 2014; Published 11 September 2014

Academic Editor: Chi-Feng Hung

Copyright (C) 2014 Loren Pickart et al. This is an open access article distributed under the Creative Commons Attribution License, which permits unrestricted use, distribution, and reproduction in any medium, provided the original work is properly cited.

\begin{abstract}
During human aging there is an increase in the activity of inflammatory, cancer promoting, and tissue destructive genes plus a decrease in the activity of regenerative and reparative genes. The human blood tripeptide GHK possesses many positive effects but declines with age. It improves wound healing and tissue regeneration (skin, hair follicles, stomach and intestinal linings, and boney tissue), increases collagen and glycosaminoglycans, stimulates synthesis of decorin, increases angiogenesis, and nerve outgrowth, possesses antioxidant and anti-inflammatory effects, and increases cellular stemness and the secretion of trophic factors by mesenchymal stem cells. Recently, GHK has been found to reset genes of diseased cells from patients with cancer or COPD to a more healthy state. Cancer cells reset their programmed cell death system while COPD patients' cells shut down tissue destructive genes and stimulate repair and remodeling activities. In this paper, we discuss GHK's effect on genes that suppress fibrinogen synthesis, the insulin/insulin-like system, and cancer growth plus activation of genes that increase the ubiquitin-proteasome system, DNA repair, antioxidant systems, and healing by the TGF beta superfamily. A variety of methods and dosages to effectively use GHK to reset genes to a healthier state are also discussed.
\end{abstract}

\section{Introduction}

According to the Administration on Aging (http://www.aoa .gov/), there were 39 million people aged 65 and older in 2009 which constituted $12 \%$ of the American population. By 2030 it is expected that $19 \%$ of the population will be over 65. With life expectancy continuing to increase, we may expect that this trend is here to stay. Unfortunately, with advanced age comes not only wisdom but also many age-related pathological conditions that account for the high rates of hospitalization, increased cost of health care and decreased quality of life. Today, more than ever, there is an urgent need to find safe, easy-to-administer, cost-effective methods, which could not only delay the onset of the age related diseases, but also restore health.

It now becomes increasingly clear that the primary cause of human aging and its attendant diseases is changes in the activity of the human genome. During aging there is an increase in the activity of inflammatory, cancer promoting, and tissue destructive genes plus a decrease in the activity of regenerative and reparative genes [1].

The most exciting discovery of the past decades is that these changes in gene activity can be reversed, often by quite simple and natural molecules [2]. Recent discoveries on the actions of the human tripeptide GHK (glycyl-L-histidyl-Llysine) to reset gene expression of human cells to a more healthy state may open a door to the therapeutic resetting of genes in the elderly. This can be useful as a preventative measure and a complimentary treatment for conditions typically associated with aging such as cancer, Alzheimer's, chronic obstructive lung disease (COPD), nephropathy, and retinopathy.

GHK was discovered during studies comparing the effect of human plasma from young persons (age 20-25) to plasma from older persons (age 50-70) on the functioning of incubated slices of human hepatic tissue. The younger plasma more effectively induced a profile associated with youth by suppressing fibrinogen synthesis. The active factor was found to be GHK. Since then numerous studies over the course of four decades demonstrated that this simple molecule improves wound healing and tissue regeneration (skin, hair follicles, bones, stomach, intestinal linings, and liver), increases collagen and glycosaminoglycans, stimulates synthesis of decorin, increases angiogenesis, and nerve outgrowth; possesses antioxidant and anti-inflammatory effects, 
and increases cellular stemness and the secretion of trophic factors by mesenchymal stem cells [3-6].

GHK's actions on gene expression were determined by the Broad Institute and, using their data, we determined that GHK increased or decreased gene expression (UP or DOWN more than 50\%) in 32.1\% of the human genes [7]. In a recent gene study, the Broad Institute's Connectivity Map was used to find potential therapeutic agents for aggressive, metastatic colon cancer [8]. The gene analysis computer program selected GHK from 1,309 bioactive molecules as the best choice to reset the diseased gene patterns to a healthier pattern. When three lines of human cancer cells (SH-SY5Y neuroblastoma cells, U937 histolytic cells, breast cancer cells) were incubated in culture with 1 to 10 nanomolar GHK, the programmed cell death system (apoptosis) was reactivated and cell growth inhibited [9]. When cells derived from the damaged areas of the lungs of COPD patients were incubated with 10 nanomolar GHK, the tripeptide recapitulated TGF beta induced genes expression patterns which led to the organization of the actin cytoskeleton and elevated the expression of integrin. This restored proper collagen contraction and remodeling by lung fibroblasts [10]. These results, combined with GHK's broad spectrum of positive actions on many systems that maintain human health, suggest that therapies using GHK might provide health benefits to the elderly.

In this paper, we discuss the following actions of GHK on genes important in healthy aging.

(1) The Suppression of Fibrinogen Synthesis. Fibrinogen is an excellent predictor of mortality especially in patients with cardiovascular complications [11, 12]. GHK was isolated as a plasma factor that suppressed fibrinogen synthesis in liver tissue and in mice.

(2) Activation of the Ubiquitin/Proteasome System (UPS). The UPS removes damaged proteins. Higher activities of the UPS appear to retard aging effects $[13,14]$.

(3) Activation of DNA Repair Genes. DNA damage is promptly repaired in young and healthy cells, however, as we age, DNA damage starts accumulating. Resetting activity of DNA repair genes can diminish deleterious effects of aging.

(4) Antioxidant Genes. Free radicals and toxic end products of lipid peroxidation are linked to atherosclerosis, cancer, cataracts, diabetes, nephropathy, Alzheimer's disease and other severe pathological conditions of aging.

(5) Suppression of Insulin and Insulin-Like Genes. The insulin family has been proposed as a negative controller of longevity; higher levels of insulin and insulin-like proteins reduce the lifespan [15].

(6) Tissue Repair by TGF Superfamily. General tissue repair by the TGF superfamily as exemplified by COPD (chronic obstructive pulmonary disease).

(7) Cancer Controlling Genes. Caspase, growth regulatory, and DNA repair genes are important in cancer suppression.
TABLE 1: GHK and fibrinogen.

\begin{tabular}{lc}
\hline Gene title & $\begin{array}{c}\text { Percent change in } \\
\text { gene expression }\end{array}$ \\
\hline Fibrinogen alpha chain, FGA & 121 \\
Fibrinogen beta chain, FGB & -475 \\
\hline
\end{tabular}

In addition to discussing GHK actions in this paper, we suggest administrative methods and dosages that should be effective in humans.

\section{Methods and Results}

2.1. Gene Expression Analysis. The connectivity map was used to acquire our gene expression data (retrieved March 5, 2013) [16]. Within the Connectivity Map repository there are three GHK gene signatures. Each signature was produced using the GeneChip HT Human Genome U133A Array. GHK was tested on 2 of the 5 cell lines used by the Connectivity Map. Two of the profiles were created using the PC3 cell line while the third used the MCF7 cell line. Our studies utilized all three gene expression profiles.

This genomic data was then analyzed using GenePattern [17]. The CEL files were processed with MAS5 and background correction. Files were then uploaded to the ComparativeMarkerSelectionViewer module in order to view fold changes for each probe set.

Since many probe sets map to the same gene we converted the fold changes in m-RNA production produced by GenePattern to percentages and then averaged all probe sets representing the same gene. It was determined that the 22,277 probe sets in the Broad data represent 13,424 genes. This ratio (1.66) was used to calculate the overall number of genes that are affected by GHK at various cutoff points (rather than probe sets). The number of genes stimulated or suppressed by GHK with a change greater than or equal to $50 \%$ is $31.2 \%$.

2.2. Fibrinogen Suppression. Fibrinogen consists of three polypeptide chains; alpha, beta, and gamma. GHK strongly suppresses the gene for the beta chain of fibrinogen. A lack of adequate FGB will effectively stop fibrinogen syntheses since equal amounts of all three polypeptide chains are needed to produce fibrinogen. See Table 1.

GHK also suppresses the production of the inflammatory cytokine interleukin-6 (IL-6) which is a main positive regulator of fibrinogen synthesis, through its interaction with fibrinogen genes [18]. In cell culture systems, GHK suppresses IL-6 secretion in skin fibroblasts and IL-6 gene expression in SZ95 sebocytes $[19,20]$.

In summary, the effects of GHK on the FGB gene plus its effects on IL-6 production imply a suppression of overall fibrinogen production.

2.3. Ubiquitin/Proteasome System. GHK stimulated gene expression in 41 UPS genes while suppressing only 1 UPS gene. See Table 2. 
TABLE 2: Ubiquitin/proteasome system and GHK.

\begin{tabular}{|c|c|c|}
\hline Up & Gene title & $\begin{array}{l}\text { Percent change in } \\
\text { gene expression }\end{array}$ \\
\hline 1 & Ubiquitin specific peptidase 29, USP29 & 1056 \\
\hline 2 & Ubiquitin protein ligase E3 component n-recognin 2, UBR2 & 455 \\
\hline 3 & Gamma-aminobutyric acid (GABA) B receptor, 1 /// ubiquitin D, GABBR1/// UBD & 310 \\
\hline 4 & Ubiquitin specific peptidase 34 , USP34 & 195 \\
\hline 5 & Parkinson protein 2, E3 ubiquitin protein ligase (parkin), PARK2 & 169 \\
\hline 6 & Ubiquitin-conjugating enzyme E2I (UBC9 homolog, yeast), UBE2I & 150 \\
\hline 7 & Ubiquitin protein ligase E3 component n-recognin 4, UBR4 & 146 \\
\hline 8 & Ubiquitin protein ligase E3B, UBE3B & 116 \\
\hline 9 & Ubiquitin specific peptidase 2, USP2 & 104 \\
\hline 10 & Ubiquitin-like modifier activating enzyme 6 , UBA6 & 104 \\
\hline 11 & Ubiquitination factor E4B (UFD2 homolog, yeast), UBE4B & 97 \\
\hline 12 & Ubiquitin-conjugating enzyme E2M (UBC12 homolog, yeast), UBE2M & 92 \\
\hline 13 & Ubiquitin-like modifier activating enzyme 7, UBA7 & 88 \\
\hline 14 & HECT, C2 and WW domain containing E3 ubiquitin protein ligase 1, HECW1 & 81 \\
\hline 15 & Proteasome (prosome, macropain) 26S subunit, ATPase, 3, PSMC3 & 81 \\
\hline 16 & Ubiquitin-conjugating enzyme E2D 1 (UBC4/5 homolog, yeast), UBE2D1 & 79 \\
\hline 17 & Proteasome (prosome, macropain) subunit, beta type, 2, PSMB2 & 79 \\
\hline 18 & Ubiquitin protein ligase E3 component n-recognin 5, UBR5 & 77 \\
\hline 19 & Ubiquitin specific peptidase 21, USP21 & 76 \\
\hline 20 & OTU domain, ubiquitin aldehyde binding 2, OTUB2 & 76 \\
\hline 21 & Proteasome (prosome, macropain) inhibitor subunit 1 (PI31), PSMF1 & 75 \\
\hline 22 & Ubiquitin-conjugating enzyme E2H (UBC8 homolog, yeast), UBE2H & 73 \\
\hline 23 & Ubiquitin-conjugating enzyme E2N (UBC13 homolog, yeast), UBE2N & 72 \\
\hline 24 & Ubiquitin carboxyl-terminal hydrolase L5, UCHL5 & 71 \\
\hline 25 & Proteasome (prosome, macropain) 26S subunit, non-ATPase, 13, PSMD13 & 70 \\
\hline 26 & Ubiquitin associated protein 1, UBAP1 & 70 \\
\hline 27 & Ubiquitin-conjugating enzyme E2B (RAD6 homolog), UBE2B & 69 \\
\hline 28 & $\begin{array}{l}\text { TMEM189-UBE2V1 readthrough /// ubiquitin-conjugating enzyme E2 variant 1, } \\
\text { TMEM189-UBE2V1/// UBE2V1 }\end{array}$ & 67 \\
\hline 29 & Proteasome (prosome, macropain) 26S subunit, non-ATPase, 1, PSMD1 & 64 \\
\hline 30 & Proteasome (prosome, macropain) 26S subunit, non-ATPase, 3, PSMD3 & 64 \\
\hline 31 & $\begin{array}{l}\text { Ariadne homolog, ubiquitin-conjugating enzyme E2 binding protein, } 1 \text { (drosophila), } \\
\text { ARIH1 }\end{array}$ & 61 \\
\hline 32 & BRCA1 associated protein-1 (ubiquitin carboxy-terminal hydrolase), BAP1 & 60 \\
\hline 33 & Ubiquitin interaction motif containing 1, UIMC1 & 60 \\
\hline 34 & Ubiquitin associated protein 2-like, UBAP2L & 57 \\
\hline 35 & Ubiquitin protein ligase E3 component n-recognin 7 (putative), UBR7 & 56 \\
\hline 36 & Ubiquitin-conjugating enzyme E2G 1 (UBC7 homolog, yeast), UBE2G1 & 54 \\
\hline 37 & Itchy E3 ubiquitin protein ligase homolog (mouse), ITCH & 54 \\
\hline 38 & Ubiquitin-conjugating enzyme E2D 4 (putative), UBE2D4 & 51 \\
\hline 39 & Proteasome (prosome, macropain) 26S subunit, non-ATPase, 10, PSMD10 & 50 \\
\hline 40 & WW domain containing E3 ubiquitin protein ligase 1, WWP1 & 50 \\
\hline 41 & Ubiquitin-like 3, UBL3 & 50 \\
\hline Down & Gene title & $\begin{array}{l}\text { Percent change in } \\
\text { gene expression }\end{array}$ \\
\hline 1 & Ubiquitin associated and $\mathrm{SH} 3$ domain containing A, UBASH3A & -89 \\
\hline
\end{tabular}


TABLE 3: GHK and DNA repair.

\begin{tabular}{lcc}
\hline $\begin{array}{l}\text { Percent change in gene } \\
\text { expression }\end{array}$ & Genes up & Genes down \\
\hline $50 \%-100 \%$ & 41 & 4 \\
$100 \%-150 \%$ & 2 & 1 \\
$150 \%-200 \%$ & 1 & 0 \\
$200 \%-250 \%$ & 2 & 0 \\
$250 \%-300 \%$ & 1 & 0 \\
\hline
\end{tabular}

TABLE 4: The most affected DNA repair genes.

\begin{tabular}{llc}
\hline Up & Gene title & $\begin{array}{c}\text { Percent change in } \\
\text { gene expression }\end{array}$ \\
\hline 1 & $\begin{array}{l}\text { Poly (ADP-ribose) polymerase } \\
\text { family, member 3, PARP3 } \\
\text { Polymerase (DNA directed), mu, } \\
\text { POLM } \\
\text { MRE11 meiotic recombination 11 } \\
\text { homolog A MRE11A }\end{array}$ & 253 \\
3 & $\begin{array}{l}\text { RAD50 homolog (S. cerevisiae) } \\
\text { RAD50 } \\
\text { Eyes absent homolog 3 } \\
\text { (Drosophila), EYA3 } \\
\text { Retinoic acid receptor, alpha, } \\
\text { RARA }\end{array}$ & 212 \\
6 & $\begin{array}{l}\text { Gene title } \\
\text { Down }\end{array}$ & 125 \\
\hline 1 & $\begin{array}{l}\text { Cholinergic receptor, nicotinic, } \\
\text { alpha 4, CHRNA4 }\end{array}$ & 123 \\
\hline
\end{tabular}

2.4. DNA Repair Genes. GHK was primarily stimulatory for DNA repair genes (47 UP, 5 DOWN). See Tables 3 and 4.

2.5. Antioxidant Genes. Among the 13,424 available genes in the Broad Institute data, we were able to identify 14 antioxidant genes in which GHK stimulates as well as two prooxidant genes that GHK suppresses. GHK increases the expression of the oxidative/inflammatory gene NF- $\kappa$ B2 103\% but also increases the expression of two inhibitors of NF- $\kappa \mathrm{B}$, TLE1 by $762 \%$ and IL18BP by $295 \%$, thus possibly inhibiting the activity of the NF- $\kappa$ B protein. See Table 5.

2.6. Insulin and Insulin-Like System. GHK stimulates 3 genes in this system and suppresses 6 genes. See Table 6.

\section{Discussion}

Even though numerous and diverse beneficial effects of GHK have been known for decades, it was not clear how one simple molecule could accomplish so much. The use of gene expression data greatly extends our understanding of GHK's effects and its potential treatments of some of the diseases and biochemical changes associated with aging. As a potential therapeutic agent GHK has a clear advantage over many other active chemicals that may also show promising results in gene profiling experiments, its gene modulating effects correspond to findings from in vivo experiments. When GHK is administered internally to an animal, it induces actions throughout the body.

The treatment of rats, mice, and pigs with GHK was shown to effectively activate systemic healing throughout the animal. For example, if GHK is injected into the thigh muscles of rats, it induces accelerated healing in implanted Hunt-Schilling wound chambers. If the GHK is injected into the thigh muscles of mice, it accelerates the healing of an experimental full thickness surgical defect wound model on its back. If injected into thigh muscles of pigs, it induces accelerates healing of full thickness surgical defect wounds on its back [37]. If GHK is injected intraperitoneally into rats, it heals tubular bone fractures [38]. Wound healing requires activation of gene expression for numerous pathways and wound healing data confirms that GHK is able to activate gene expression in animals [39-45].

There is still not enough information to translate gene profiling data into biological effects. However, based on the documented activity of GHK in vivo, we can predict the following beneficial actions from our gene profiling data.

3.1. Fibrinogen. Fibrinogen, the protein which is used to make blood clots, is also a strong predictor of mortality in cardiovascular patients. After vascular incidents, such as myocardial infarction, fibrinogen concentrations increase sharply. The free, unclotted fibrinogen protein increases the "stickiness" of red blood cells which stack together forming rouleaux. This increases the time of the "solid" blood state which decreases blood flow through the microcirculation where blood flows like a thixotropic fluid, switching between a solid phase and a liquid phase, somewhat like toothpaste. As a solid, it stops oxygen and nutrient flow to the tissues. This, in itself, can cause tissue damage.

The gene data on GHK's suppression of FGB (the fibrinogen beta chain) combined with its actions on lowering IL-6 secretion on fibroblasts and sebocytes appears to be sufficient to explain its lowering effect on fibrinogen.

3.2. Ubiquitin Proteasome System. The ubiquitin proteasome system (UPS) functions in the removal of damaged or misfolded proteins. Aging is a natural process that is characterized by a progressive accumulation of unfolded, misfolded, or aggregated proteins. In particular, the proteasome is responsible for the removal of normal as well as damaged or misfolded proteins. Recent work has demonstrated that proteasome activation by either genetic means or use of compounds retards aging $[13,14]$.

In our screening of UPS genes with a percent change of at least $\pm 50 \%$, GHK increased gene expression in 41 UPS genes while suppressing 1 UPS gene. Thus, it should have a positive effect on this system $[13,14,46]$.

3.3. DNA Repair. It is estimated that normal metabolic activities and environmental factors such as UV light and radiation can cause DNA damage, resulting in somewhere between 1000 and as many as 1 million individual molecular lesions per cell per day. Lack of sufficient DNA repair is 
TABLE 5: GHK effects on antioxidant genes.

\begin{tabular}{|c|c|c|c|}
\hline Up & Genes & $\begin{array}{l}\text { Percent change in } \\
\text { gene expression }\end{array}$ & Comments \\
\hline 1 & TLE1 & 762 & Inhibits the oxidative/inflammatory gene NF- $\kappa \mathrm{B}[21]$. \\
\hline 2 & SPRR2C & 721 & $\begin{array}{l}\text { This proline-rich, antioxidant protein protects outer skin cells from } \\
\text { oxidative damage from ROS. When the ROS level is low, the protein } \\
\text { remains in the outer cell membrane but when the ROS level is high, the } \\
\text { protein clusters around the cell's DNA to protect it }[22,23] \text {. }\end{array}$ \\
\hline 3 & ITGB4 & 609 & $\begin{array}{l}\text { Upregulation of ITGB4 promotes wound repair ability and antioxidative } \\
\text { ability [24]. }\end{array}$ \\
\hline 4 & APOM & 403 & $\begin{array}{l}\text { Binds oxidized phospholipids and increases the antioxidant effect of HDL } \\
\text { [25]. }\end{array}$ \\
\hline 5 & PON3 & 319 & $\begin{array}{l}\text { Absence of PON3 (paraoxonase } 3 \text { ) in mice resulted in increased rates of } \\
\text { early fetal and neonatal death. Knockdown of PON3 in human cells } \\
\text { reduced cell proliferation and total antioxidant capacity [26]. }\end{array}$ \\
\hline 6 & IL18BP & 295 & $\begin{array}{l}\text { The protein encoded by this gene is an inhibitor of the proinflammatory } \\
\text { cytokine IL18. IL18BP abolished IL18 induction of interferon-gamma } \\
\text { (IFNgamma), IL8, and activation of NF- } \kappa \text { B in vitro. Blocks neutrophil } \\
\text { oxidase activity [27]. }\end{array}$ \\
\hline 7 & $\mathrm{HEPH}$ & 217 & $\begin{array}{l}\text { Inhibits the conversion of } \mathrm{Fe}(2+) \text { to } \mathrm{Fe}(3+) \text {. HEPH increases iron efflux, } \\
\text { lowers cellular iron levels, suppresses reactive oxygen species production, } \\
\text { and restores mitochondrial transmembrane potential [28]. }\end{array}$ \\
\hline 8 & FABP1 & 186 & $\begin{array}{l}\text { Reduces intracellular ROS level. Plays a significant role in reduction of } \\
\text { oxidative stress }[29,30] .\end{array}$ \\
\hline 9 & PON1 & 149 & $\begin{array}{l}\text { PON1 (paraoxonase 1) is a potent antioxidant and a major } \\
\text { anti-atherosclerotic component of high-density lipoprotein [31]. }\end{array}$ \\
\hline 10 & MT3 & 142 & $\begin{array}{l}\text { Metallothioneins (MTs) display in vitro oxyradical scavenging capacity, } \\
\text { suggesting that they may specifically neutralize hydroxyl radicals. } \\
\text { Metallothioneins and metallothionein-like proteins isolated from mouse } \\
\text { brain act as neuroprotective agents by scavenging superoxide radicals } \\
{[32,33] \text {. }}\end{array}$ \\
\hline 11 & PTGS2 & 120 & Produces cyclooxygenase-II (COX-II) which has antioxidant activities [34] \\
\hline 12 & $\mathrm{NF}-\kappa \mathrm{B} 2$ & 103 & $\begin{array}{l}\mathrm{NF}-\kappa \mathrm{B} \text {, an oxidative/inflammatory protein, is involved in cellular responses } \\
\text { to stimuli such as stress, cytokines, free radicals, ultraviolet irradiation, } \\
\text { oxidized LDL, and bacterial or viral antigens [21]. }\end{array}$ \\
\hline 13 & NFE2L2 & 56 & $\begin{array}{l}\text { Nuclear respiratory factor } 2 \text { helps activate antioxidant responsive element } \\
\text { regulated genes which contribute to the regulation of the cellular } \\
\text { antioxidant defense systems [35]. }\end{array}$ \\
\hline 14 & PTGS1 & 50 & Produces cyclooxygenase-I (COX-I) which has antioxidant activity [34]. \\
\hline Down & Genes & $\begin{array}{l}\text { Percent change in } \\
\text { gene expression }\end{array}$ & Comments \\
\hline 1 & IL17A & -1018 & $\begin{array}{l}\text { This strongly suppressed cytokine can stimulate the expression of IL6 and } \\
\text { cyclooxygenase-2 (PTGS2/COX-2), as well as enhancing the production of } \\
\text { nitric oxide (NO). High levels of this cytokine are associated with several } \\
\text { chronic inflammatory diseases including rheumatoid arthritis, psoriasis, } \\
\text { and multiple sclerosis (NCBI GENE entry). }\end{array}$ \\
\hline 2 & TNF & -115 & $\begin{array}{l}\text { GHK suppresses this prooxidant TNF gene which inhibits the antioxidant } \\
\text { IL18 [36]. }\end{array}$ \\
\hline
\end{tabular}

considered a cause of cell senescence, programmed cell death, and unregulated cell division, which can lead to the formation of a tumor that is cancerous [47-50].

GHK was stimulatory for DNA repair genes (47 stimulated, 5 suppressed) suggesting an increased DNA repair activity.
3.4. Antioxidant Defense. Free radicals and toxic end products of lipid peroxidation are linked to atherosclerosis, cancer, cataracts, diabetes, nephropathy, Alzheimer's disease, and other severe pathological conditions of aging. Reactive oxygen species (ROS) and reactive carbonyl species (RCS) are produced in cells in small quantities under physiological 
TABLE 6: GHK and insulin/insulin-like genes.

\begin{tabular}{|c|c|c|}
\hline Up & Gene title & $\begin{array}{l}\text { Percent change in } \\
\text { gene expression }\end{array}$ \\
\hline 1 & Insulin-like 6, INSL6 & 188 \\
\hline 2 & $\begin{array}{l}\text { Insulin-like growth factor } 2 \\
\text { mRNA binding protein } 3 \text {, } \\
\text { IGF2BP3 }\end{array}$ & 136 \\
\hline 3 & $\begin{array}{l}\text { Insulin-like growth factor } \\
\text { binding protein } 3 \text {, IGFBP3 }\end{array}$ & 82 \\
\hline Down & Gene title & $\begin{array}{l}\text { Percent change in } \\
\text { gene expression }\end{array}$ \\
\hline 1 & $\begin{array}{l}\text { Insulin-like growth factor } 1 \\
\text { (somatomedin C), IGF1 }\end{array}$ & -522 \\
\hline 2 & $\begin{array}{l}\text { Insulin receptor-related receptor, } \\
\text { INSRR }\end{array}$ & -437 \\
\hline 3 & Insulin, INS & -289 \\
\hline 4 & $\begin{array}{l}\text { Insulin-like } 3 \text { (Leydig cell), } \\
\text { INSL3 }\end{array}$ & -188 \\
\hline 5 & $\begin{array}{l}\text { Insulin-like growth factor } \\
\text { binding protein } 7, \text { IGFBP7 }\end{array}$ & -110 \\
\hline 6 & Insulin-like 5, INSL5 & -101 \\
\hline
\end{tabular}

conditions and play an important role in cell signaling and immune defense. A robust antioxidant network maintains balance between free radical production and scavenging, ensuring that the overall damage from free radicals is low. However, in the course of aging and in pathological conditions such as inflammation, the balance may shift toward free radical accumulation that can lead to oxidative stress and eventually to cell death [51].

GHK increases gene expression of 14 antioxidant genes and suppresses the expression of 2 prooxidant genes. It increases the expression of the oxidative/inflammatory gene NF- $\kappa$ B2 103\% but also increases the expression of two inhibitors of NF- $\kappa$ B, TLE1 by $762 \%$ and IL18BP by $295 \%$; thus, it possibly inhibits the activity of the NF- $\kappa$ B protein.

GHK also possesses antioxidant activities in cell culture and in vivo.

In dermal wound healing in rats, GHK, attached to biotin to bind it to collagen pads covering wounds, produced a higher production of protein antioxidants in the wound tissue. Superoxide dismutase was increased $80 \%$ while catalase was increased $56 \%[52,53]$. GHK reduced gastric mucosal damage by $75 \%$ against lipid peroxidation by oxygen-derived free radicals induced by acute intragastric administration of ethanol [54].

Interleukin 1 beta can induce serious oxidative damage to cultured cells $[55,56]$. GHK markedly reduced oxidative damage by interleukin 1-beta to cultured insulin secreting pancreatic cells [57].

In another study, GHK entirely blocked the extent of in vitro $\mathrm{Cu}(2+)$-dependent oxidation of low density lipoproteins (LDL). Treatment of LDL with 5 microM $\mathrm{Cu}(2+)$ for 18 hours in phosphate buffered saline (PBS) resulted in extensive oxidation as determined by the content of thiobarbituric acid reactive substances. Oxidation was entirely blocked by GHK.
In comparison, copper, zinc-superoxide dismutase provided only $20 \%$ protection [58].

Acrolein, a well-known carbonyl toxin, is produced by lipid peroxidation of polyunsaturated fatty acids. GHK directly blocks the formation of 4-hydroxynonenal and acrolein toxins created by carbonyl radicals that cause fatty acid decomposition [59, 60]. GHK also blocks lethal ultraviolet radiation damage to cultured skin keratinocytes by binding and inactivating reactive carbonyl species such as 4hydroxynoneal, acrolein, malondialdehye, and glyoxal [61].

Iron has a direct role in the initiation of lipid peroxidation. An $\mathrm{Fe}(2+) / \mathrm{Fe}(3+)$ complex can serve as an initiator of lipid oxidation. The major storage site for iron in serum and tissue is ferritin and the superoxide anion can promote the mobilization of iron from ferritin which can catalyze lipid peroxidation. $\mathrm{GHK}: \mathrm{Cu}(2+)$ produced an $87 \%$ inhibition of iron release from ferritin by apparently blocking iron's exit channels from the protein [62].

3.5. Insulin and Insulin-Like Pathways. The insulin/IGF-1like receptor pathway is a contributor to the biological aging process in many organisms. The gene expression data suggests that GHK suppresses this system as 6 of 9 of the affected insulin/IGF-1 genes are suppressed.

Insulin/IGF-1-like signaling is conserved from worms to humans. In vitro experiments show that mutations that reduce insulin/IGF-1 signaling have been shown to decelerate the degenerative aging process and extend lifespan in many organisms, including mice and possibly humans. Reduced IGF-1 signaling is also thought to contribute to the "antiaging" effects of calorie restriction [63].

3.6. $C O P D$. COPD (chronic obstructive lung disease) is a leading cause of death in the world. It is a deadly and painful disease of the lungs that causes difficulty in breathing. In people with COPD, the tissues necessary to support the physical shape and function of the lungs are destroyed. COPD is most often caused by tobacco smoking and longterm exposure to air pollution but is also a component of normal aging. As the lungs get older, the elastic properties decrease, and the tensions that develop can result in areas of emphysema.

The most explored of GHK's actions is the repair of damaged tissues (skin, hair follicles, stomach and intestinal linings, and boney tissue) either by the use of copper-peptide containing creams or by induction of systemic healing. Campbell et al. found that GHK's resetting of gene expression of fibroblasts from COPD patients fits into this category of tissue repair via the TGF beta superfamily. Campbell et al. found that GHK directly increases TGF beta and other family members which activate the repair process [10].

Treatment of human fibroblasts with GHK recapitulated TGF beta-induced gene expression patterns, led to the organization of the actin cytoskeleton and elevated the expression of integrin betal. Furthermore, addition of GHK or TGF beta restored collagen I contraction and remodeling by fibroblasts derived from COPD lungs compared to fibroblasts from former smokers without COPD. 
On another note, persons with severe COPD use air inhalation systems that pump misty, water-filled air in and out of the lungs. Often steroids are added to the solution to suppress the lung inflammation, while this provides shortterm help, it also inhibits lung repair. In theory, GHK could be infused into the blood stream of patients to repair the lung tissue, added to a misting solution or used in combination of a carrier like DMSO along with GHK (use a 1:1 molar ratio of GHK to DMSO). DMSO and GHK or GHK : $\mathrm{Cu}(2+)$ has always worked well together on wound healing. DMSO has been used in the past as a treatment for COPD, so there should be few safety issues.

Also, it may be possible to induce more extensive rebuilding of lung tissue. The mixture of GHK, transferrin, and somatostatin was sufficient to promote branching in the absence of serum in organ culture, all of which could be added to the misting solution [64].

3.7. Cancer. In 2010, Hong et al. identified 54 genes associated with aggressive, metastatic, human colon cancer [8]. The Broad Institute's Connectivity Map was used to find compounds that reverse the differential expressions of these genes. The results indicated that two wound healing and skin remodeling molecules, GHK at 1 micromolar and securinine at 18 micromolar, could significantly reverse the differential expression of these genes and suggested that they may have a therapeutic effect on the metastasis-prone patients.

Normal healthy cells have checkpoint systems to selfdestruct if they are synthesizing DNA incorrectly through programmed cell death or the apoptosis system. Matalka et al. demonstrated that $\mathrm{GHK}$, at 1 to 10 nanomolar, reactivated the apoptosis system, as measured by caspases 3 and 7, and inhibited the growth of human SH-SY5Y neuroblastoma cells, human U937 histiocytic lymphoma cells, and human breast cancer cells [9]. In contrast, the GHK accelerated the growth of healthy human NIH-3T3 fibroblasts.

Our analysis of GHK's actions found that it increased gene expression in 6 of the 12 human caspase genes that activate apoptosis. In 31 other genes, GHK altered the pattern of gene expression in a manner that would be expected to inhibit cancer growth. In DNA repair genes there was an increase (47 UP, 5 DOWN) [7]. These results support the idea that GHK may help slow or suppress cancer growth.

Linus Pauling's group once used a copper tripeptide, GlyGly-His: $\mathrm{Cu}(2+)$ and ascorbic acid as a cancer treatment method. In a recent paper, we used their basic method but with $\mathrm{GHK}: \mathrm{Cu}(2+)$ and ascorbic acid, which strongly suppressed sarcoma 180 in mice without any evident distress to the animals [7]. GHK altered gene expression in 84 genes (caspases, cytokines, and DNA repair genes) in a manner that would be expected to suppress cell growth. On skin, GHK seems to act most strongly in the late stage of healing, called remodeling, where cellular migration into the wound area is stopped and cellular debris is removed. The anticancer actions of small copper peptides may be a side effect of this system.

The use of $\mathrm{GHK}: \mathrm{Cu}(2+)$ and ascorbic acid should be investigated in more detail. The mice treated in this manner appeared to remain very healthy and active, in contrast to the toxicities of current cancer chemotherapy.

3.8. GHK as a Clinical Treatment. GHK, abundantly available at low cost in bulk quantities, is a potential treatment for a variety of disease conditions associated with aging. The molecule is very safe and no issues have ever arisen during its use as a skin cosmetic or in human wound healing studies.

GHK has a very high affinity for $\mathrm{Cu}(2+)$ (pK of association $=16.4$ ) and can easily obtain copper from the blood's albumin bound $\mathrm{Cu}(2+)$ ( $\mathrm{pK}$ of association $=16.2$ ) [3]. Most of our key experiments used a 1:1 mixture of copper-free $\mathrm{GHK}$ and $\mathrm{GHK}: \mathrm{Cu}(2+)$. In wound healing experiments, the addition of copper strongly enhanced healing. However, others often obtain effective results without added copper.

Cells within tissues are under the influence of many other regulatory molecules. Thus, GHK would be expected to influence the cells' gene expression to be more similar to that of a person of age 20-25, an age when the afflictions of aging are very rare. Based on our studies, in which GHK was injected intraperitoneally once daily to induce systemic wound healing throughout the body, we estimate about 100200 mgs of GHK will produce therapeutic actions in humans. But even this may overestimate the necessary effective dosage of the molecule. Most cultured cells respond maximally to GHK at 1 nanoM. GHK has a half-life of about 0.5 to 1 hour in plasma and two subsequent tissue repair studies in rats found that injecting GHK intraperitoneally 10 times daily lowered the necessary dosage by approximately 100-fold in contrast to our earlier studies $[38,65]$.

The most likely effective dosage of GHK was given to rats for healing bone fractures. This mixture of small molecules included Gly-His-Lys $(0.5 \mu \mathrm{g} / \mathrm{kg})$, dalargin $(1.2 \mu \mathrm{g} / \mathrm{kg})$ (an opioid-like synthetic drug), and the biological peptide thymogen $(0.5 \mu \mathrm{g} / \mathrm{kg})$ (L-glutamyl-L-tryptophan) to heal bones. The total peptide dosage is about $2.2 \mu \mathrm{g} / \mathrm{kg}$ or, if scaled for the human body, about $140 \mu \mathrm{g}$ per injection with 10 treatments per day $[38,65]$.

The use of portable continuous infusion pumps for a treatment might maintain an effective level in the plasma and extracellular fluid with the need for much less GHK. Possibly the peptide could be administered with a transdermal patch [66]. Another approach could be to use peptide-loaded liposomes as an oral delivery system for uptake into the intestinal wall without significant breakdown $[67,68]$.

\section{Conclusion}

Most current theories and therapies to treat disease tend to target only one biochemical reaction or pathway. But for human aging, our data suggests that we must think of simultaneously resetting hundreds to thousands of genes to protect at-risk tissues and organs. GHK may be a step towards this gene resetting goal.

\section{Conflict of Interests}

The authors declare that there is no conflict of interests regarding the publication of this paper. 


\section{Acknowledgments}

The authors would like to thank Idelle Musiek, MFA, and Genevieve Pickart, MA, for their invaluable work in the paper preparation.

\section{References}

[1] C. Franceschi and J. Campisi, "Chronic inflammation (inflammaging) and its potential contribution to age-associated diseases," The Journals of Gerontology, vol. 69, supplement 1, pp. s4-s9, 2014.

[2] A. Brunet and S. L. Berger, "Epigenetics of aging and agingrelated disease," Journals of Gerontology A: Biological Sciences and Medical Sciences, vol. 69, supplement 1, p. S1720, 2014.

[3] L. Pickart, "The human tri-peptide GHK and tissue remodeling," Journal of Biomaterials Science, Polymer Edition, vol. 19, no. 8, pp. 969-988, 2008.

[4] L. Pickart, "The human tripeptide GHK (Glycyl-L-HistidylL-Lysine)," in The Copper Switch, and The Treatment of the Degenerative Conditions of Aging, R. Klatz and R. Goldman, Eds., chapter 36, pp. 301-312, American Academy of Anti-Aging Medicine, 2009.

[5] H. R. Choi, Y. A. Kang, S. J. Ryoo et al., "Stem cell recovering effect of copper-free GHK in skin," Journal of Peptide Science, vol. 18, Article ID 685G690, pp. 685-690, 2012.

[6] S. Jose, M. L. Hughbanks, B. Y. Binder, G. C. Ingavle, and J. K. Leach, "Enhanced trophic factor secretion by mesenchymal stem/stromal cells with Glycine-Histidine-Lysine (GHK)modified alginate hydrogels," Acta Biomaterialia, vol. 10, pp. 1955-1964, 2014.

[7] L. Pickart, J. M. Vasquez-Soltero, F. D. Pickart, and J. Majnarich, "GHK, the human skin remodeling peptide, induces anti-cancer expression of numerous caspase, growth regulatory, and DNA repair genes," Journal of Analytical Oncology, vol. 3, no. 2, pp. 79-87, 2014.

[8] Y. Hong, T. Downey, K. W. Eu, P. K. Koh, and P. Y. Cheah, "A 'metastasis-prone' signature for early-stage mismatch-repair proficient sporadic colorectal cancer patients and its implications for possible therapeutics," Clinical and Experimental Metastasis, vol. 27, no. 2, pp. 83-90, 2010.

[9] L. E. Matalka, A. Ford, and M. T. Unlap, "The tripeptide, GHK, induces programmed cell death in SH-SY5Y neuroblastoma cells," Journal of Biotechnology \& Biomaterials, vol. 2, pp. 1-4, 2012.

[10] J. D. Campbell, J. E. McDonough, J. E. Zeskind et al., "A gene expression signature of emphysema-related lung destruction and its reversal by the tripeptide GHK," Genome Medicine, vol. 4, article 67, 2012.

[11] K. Yano, J. S. Grove, R. Chen, B. L. Rodriguez, J. D. Curb, and R. P. Tracy, "Plasma fibrinogen as a predictor of total and cause-specific mortality in elderly Japanese-American men," Arteriosclerosis, Thrombosis, and Vascular Biology, vol. 21, no. 6, pp. 1065-1070, 2001.

[12] M. Benderly, E. Graff, H. Reicher-Reiss, S. Behar, D. Brunner, and U. Goldbourt, "Fibrinogen is a predictor of mortality in coronary heart disease patients," Arteriosclerosis, Thrombosis, and Vascular Biology, vol. 16, no. 3, pp. 351-356, 1996.

[13] E. Kevei and T. Hoppe, "Ubiquitin sets the timer: impacts on aging and longevity," Nature Structural \& Molecular Biology, vol. 21, pp. 290-292, 2014.
[14] N. Chondrogianni, M. Sakellari, M. Lefaki, N. Papaevgeniou, and E. S. Gonos, "Proteasome activation delays aging in vitro and in vivo," Free Radical Biology \& Medicine C, vol. 71, pp. 303320, 2014.

[15] C. Kenyon, "The first long-lived mutants: discovery of the insulin/IGF-1 pathway for ageing," Philosophical Transactions of the Royal Society B, vol. 366, no. 1561, pp. 9-16, 2011.

[16] J. Lamb, E. D. Crawford, D. Peck et al., "The connectivity map: using gene-expression signatures to connect small molecules, genes, and disease," Science, vol. 313, no. 5795, pp. 1929-1935, 2006.

[17] M. Reich, T. Liefeld, J. Gould, J. Lerner, P. Tamayo, and J. P. Mesirov, "GenePattern 2.0," Nature Genetics, vol. 38, no. 5, pp. 500-501, 2006.

[18] C. L. Carty, P. Heagerty, S. R. Heckbert et al., "Interaction between fibrinogen and IL-6 genetic variants and associations with cardiovascular disease risk in the cardiovascular health study," Annals of Human Genetics, vol. 74, no. 1, pp. 1-10, 2010.

[19] S. Schagen, R. Voegeli, D. Imfeld, T. Schreier, and C. Zouboulis, "Lipid regulation in SZ95 sebocytes by glycyl-histidyl-lysine," in Proceedings of the 16th European Academy of Dermatology and Venereology Congress, May 2007.

[20] A. Gruchlik, M. Jurzak, E. W. A. Chodurek, and Z. Dzierzewicz, "Effect of Gly-Gly-His, Gly-His-Lys and their copper complexes on TNF- $\alpha$-dependent IL-6 secretion in normal human dermal fibroblasts," Acta Poloniae Pharmaceutica, vol. 69, no. 6, pp. 1303-1306, 2012.

[21] N. Mariappan, C. M. Elks, S. Sriramula et al., "NF- $\kappa$ B-induced oxidative stress contributes to mitochondrial and cardiac dysfunction in type II diabetes," Cardiovascular Research, vol. 85, no. 3, pp. 473-483, 2010.

[22] W. P. Vermeij, B. I. Florea, S. Isenia, A. Alia, J. Brouwer, and C. Backendorf, "Proteomic identification of in vivo interactors reveals novel function of skin cornification proteins," Journal of Proteome Research, vol. 11, no. 6, pp. 3068-3076, 2012.

[23] W. P. Vermeij, A. Alia, and C. Backendorf, "ROS quenching potential of the epidermal cornified cell envelope," Journal of Investigative Dermatology, vol. 131, no. 7, pp. 1435-1441, 2011.

[24] C. Liu, H.-J. Liu, Y. Xiang, Y.-R. Tan, X.-L. Zhu, and X.-Q. Qin, "Wound repair and anti-oxidative capacity is regulated by ITGB4 in airway epithelial cells," Molecular and Cellular Biochemistry, vol. 341, no. 1-2, pp. 259-269, 2010.

[25] S. Elsøe, J. Ahnström, C. Christoffersen et al., "Apolipoprotein $\mathrm{M}$ binds oxidized phospholipids and increases the antioxidant effect of HDL," Atherosclerosis, vol. 221, no. 1, pp. 91-97, 2012.

[26] S. L. Kempster, G. Belteki, D. Licence, D. S. Charnock-Jones, and G. C. S. Smith, "Disruption of paraoxonase 3 impairs proliferation and antioxidant defenses in human A549 cells and causes embryonic lethality in mice," The American Journal of Physiology-Endocrinology and Metabolism, vol. 302, no. 1, pp. E103-E107, 2012.

[27] D. Novick, S.-H. Kim, G. Fantuzzi, L. L. Reznikov, C. A. Dinarello, and M. Rubinstein, "Interleukin-18 binding protein: a novel modulator of the Th1 cytokine response," Immunity, vol. 10, no. 1, pp. 127-136, 1999.

[28] N. Song, J. Wang, H. Jiang, and J. Xie, "Ferroportinl and hephaestin overexpression attenuate iron-induced oxidative stress in MES23.5 dopaminergic cells," Journal of Cellular Biochemistry, vol. 110, no. 5, pp. 1063-1072, 2010.

[29] Y. Gong, G. Wang, Y. Gong, J. Yan, Y. Chen, and F. J. Burczynski, "Hepatoprotective role of liver fatty acid binding protein in 
acetaminophen induced toxicity," BMC Gastroenterology, vol. 14, article 44, 2014.

[30] G. Wang, Y. Gong, J. Anderson et al., "Antioxidative function of L-FABP in L-FABP stably transfected Chang liver cells," Hepatology, vol. 42, no. 4, pp. 871-879, 2005.

[31] M. Rosenblat, R. Karry, and M. Aviram, "Paraoxonase 1 (PON1) is a more potent antioxidant and stimulant of macrophage cholesterol efflux, when present in HDL than in lipoproteindeficient serum: relevance to diabetes," Atherosclerosis, vol. 187, no. 1, pp. 74.el-74.e10, 2006.

[32] S. Hussain, W. Slikker Jr., and S. F. Ali, "Role of metallothionein and other antioxidants in scavenging superoxide radicals and their possible role in neuroprotection," Neurochemistry International, vol. 29, no. 2, pp. 145-152, 1996.

[33] A. Viarengo, B. Burlando, N. Ceratto, and I. Panfoli, "Antioxidant role of metallothioneins: a comparative overview.", Cellular and Molecular Biology, vol. 46, no. 2, pp. 407-417, 2000.

[34] G. E. Henry, R. A. Momin, M. G. Nair, and D. L. Dewitt, "Antioxidant and cyclooxygenase activities of fatty acids found in food," Journal of Agricultural and Food Chemistry, vol. 50, no. 8, pp. 2231-2234, 2002.

[35] X. L. Chen and C. Kunsch, "Induction of cytoprotective genes through Nrf2/antioxidant response element pathway: a new therapeutic approach for the treatment of inflammatory diseases," Current Pharmaceutical Design, vol. 10, no. 8, pp. 879891, 2004.

[36] N. Mariappan, R. N. Soorappan, M. Haque, S. Sriramula, and J. Francis, "TNF- $\alpha$-induced mitochondrial oxidative stress and cardiac dysfunction: restoration by superoxide dismutase mimetic Tempol," The American Journal of Physiology-Heart and Circulatory Physiology, vol. 293, no. 5, pp. H2726-H2737, 2007.

[37] L. Pickart, "Method of using copper(II) containing compounds to accelerate wound healing," United States Patent 5164367, 1992, http://www.freepatentsonline.com/5164367.html.

[38] V. Y. Cherdakov, M. Y. Smakhtin, G. M. Dubrovin, V. T. Dudka, and I. I. Bobyntsev, "Synergetic antioxidant and reparative action of thymogen, dalargin and peptide Gly-His-Lys in tubular bone fractures," Experimental Biology and Medicine, vol. 4, pp. 15-20, 2010.

[39] P. V. Peplow and G. D. Baxter, "Gene expression and release of growth factors during delayed wound healing: A review of studies in diabetic animals and possible combined laser phototherapy and growth factor treatment to enhance healing," Photomedicine and Laser Surgery, vol. 30, no. 11, pp. 617-636, 2012.

[40] K. Deonarine, M. C. Panelli, M. E. Stashower et al., "Gene expression profiling of cutaneous wound healing," Journal of Translational Medicine, vol. 5, article 11, 2007.

[41] P. J. Murray and S. T. Smale, "Restraint of inflammatory signaling by interdependent strata of negative regulatory pathways," Nature Immunology, vol. 13, no. 10, pp. 916-924, 2012.

[42] S. Kachgal, K. A. Mace, and N. J. Boudreau, "The dual roles of homeobox genes in vascularization and wound healing," Cell Adhesion and Migration, vol. 6, no. 6, pp. 457-470, 2012.

[43] K. R. Yu and K. S. Kang, "Aging-related genes in mesenchymal stem cells: a mini-review," Gerontology, vol. 59, pp. 557-563, 2013.

[44] T. Arodz, D. Bonchev, and R. F. Diegelmann, "A network approach to wound healing," Advances in Wound Care, vol. 2, no. 9, pp. 499-509, 2013.
[45] S. Lamouille, J. Xu, and R. Derynck, "Molecular mechanisms of epithelial-mesenchymal transition," Nature Reviews Molecular Cell Biology, vol. 15, pp. 178-196, 2014.

[46] N. R. Jana, "Protein homeostasis and aging: role of ubiquitin protein ligases," Neurochemistry International, vol. 60, no. 5, pp. 443-447, 2012.

[47] P. J. Hohensinner, J. J. Goronzy, and C. M. Weyand, "Targets of immune regeneration in rheumatoid arthritis," Mayo Clinic Proceedings, vol. 89, no. 4, pp. 563-575, 2014.

[48] A. Trusina, "Stress induced telomere shortening: longer life with less mutations?" BMC Systems Biology, vol. 8, article 27, 2014.

[49] B. Debrabant, M. Soerensen, F. Flachsbart et al., "Human longevity and variation in DNA damage response and repair: study of the contribution of sub-processes using competitive gene-set analysis," European Journal of Human Genetics, vol. 22, no. 9, pp. 1131-1136, 2014.

[50] H. Lodish, A. Berk, P. Matsudaira et al., Mollecular Biology of the Cell, W.H. Freeman, New York, NY, USA, 2004.

[51] I. S. Young and J. V. Woodside, "Antioxidants in health and disease," Journal of Clinical Pathology, vol. 54, no. 3, pp. 176-186, 2001.

[52] V. Arul, D. Gopinath, K. Gomathi, and R. Jayakumar, "Biotinylated GHK peptide incorporated collagenous matrix: A novel biomaterial for dermal wound healing in rats," Journal of Biomedical Materials Research B Applied Biomaterials, vol. 73, no. 2, pp. 383-391, 2005.

[53] V. Arul, R. Kartha, and R. Jayakumar, "A therapeutic approach for diabetic wound healing using biotinylated GHK incorporated collagen matrices," Life Sciences, vol. 80, no. 4, pp. 275284, 2007.

[54] M. Alberghina, G. Lupo, G. La Spina et al., "Cytoprotective effect of copper(II) complexes against ethanol-induced damage to rat gastric mucosa," Journal of Inorganic Biochemistry, vol. 45, no. 4, pp. 245-259, 1992.

[55] K. Fukuda, M. Oh, S. Asada et al., "Sodium hyaluronate inhibits interleukin-1-evoked reactive oxygen species of bovine articular chondrocytes," Osteoarthritis and Cartilage, vol. 9, no. 4, pp. 390-392, 2001.

[56] B. Meier, H. H. Radeke, S. Selle et al., "Human fibroblasts release reactive oxygen species in response to interleukin-1 or tumour necrosis factor- $\alpha$," Biochemical Journal, vol. 263, no. 2, pp. 539545, 1989.

[57] C. Vinci, V. Caltabiano, A. M. Santoro et al., "Copper addition prevents the inhibitory effects of interleukin on rat pancreatic islets," Diabetologia, vol. 38, no. 1, pp. 39-45, 1995.

[58] C. E. Thomas, "The influence of medium components on $\mathrm{Cu}^{2+}$-dependent oxidation of low-density lipoproteins and its sensitivity to superoxide dismutase," Biochimica et Biophysica Acta, vol. 1128, no. 1, pp. 50-57, 1992.

[59] G. Beretta, E. Arlandini, R. Artali, J. M. G. Anton, and R. M. Facino, "Acrolein sequestering ability of the endogenous tripeptide glycyl-histidyl-lysine (GHK): characterization of conjugation products by ESI-MSn and theoretical calculations," Journal of Pharmaceutical and Biomedical Analysis, vol. 47, no. 3, pp. 596-602, 2008.

[60] G. Beretta, R. Artali, L. Regazzoni, M. Panigati, and R. M. Facino, "Glycyl-histidyl-lysine (GHK) is a quencher of $\alpha, \beta$ 4-hydroxy-trans-2-nonenal: a comparison with carnosine. Insights into the mechanism of reaction by electrospray ionization mass spectrometry, $1 \mathrm{H}$ NMR, and computational techniques," Chemical Research in Toxicology, vol. 20, no. 9, pp. 1309-1314, 2007. 
[61] J. Cebrian, A. Messeguer, R. Facino, and J. García Antón, "New anti-RNS and -RCS products for cosmetic treatment," International Journal of Cosmetic Science, vol. 27, no. 5, pp. 271278, 2005.

[62] D. M. Miller, D. DeSilva, L. Pickart, and S. D. Aust, "Effects of glycyl-histidyl-lysyl chelated $\mathrm{Cu}(\mathrm{II})$ on ferritin dependent lipid peroxidation," Advances in Experimental Medicine and Biology, vol. 264, pp. 79-84, 1990.

[63] C. J. Kenyon, “The genetics of ageing," Nature, vol. 464, pp. 504512,2010

[64] S. R. Hilfer, S. L. Schneck, and J. W. Brown, "The effect of culture conditions on cytodifferentiation of fetal mouse lung respiratory passageways," Experimental Lung Research, vol. 10, no. 2, pp. 115-136, 1986.

[65] M. Y. Smakhtin, A. I. Konoplya, L. A. Severyanova, A. A. Kurtseva, and V. Y. Cherdakov, "Reparative activity of different functional group peptides in hepatopathyes," Experimental Biology and Medicine, vol. 3, pp. 11-17, 2006.

[66] J. J. Hostynek, F. Dreher, and H. I. Maibach, "Human skin penetration of a copper tripeptide in vitro as a function of skin layer," Inflammation Research, vol. 60, no. 1, pp. 79-86, 2011.

[67] P. Li, H. M. Nielsen, and A. Müllertz, "Oral delivery of peptides and proteins using lipid-based drug delivery systems," Expert Opinion on Drug Delivery, vol. 9, no. 10, pp. 1289-1304, 2012.

[68] J. Swaminathan and C. Ehrhardt, "Liposomal delivery of proteins and peptides," Expert Opinion on Drug Delivery, vol. 9, no. 12, pp. 1489-1503, 2012. 

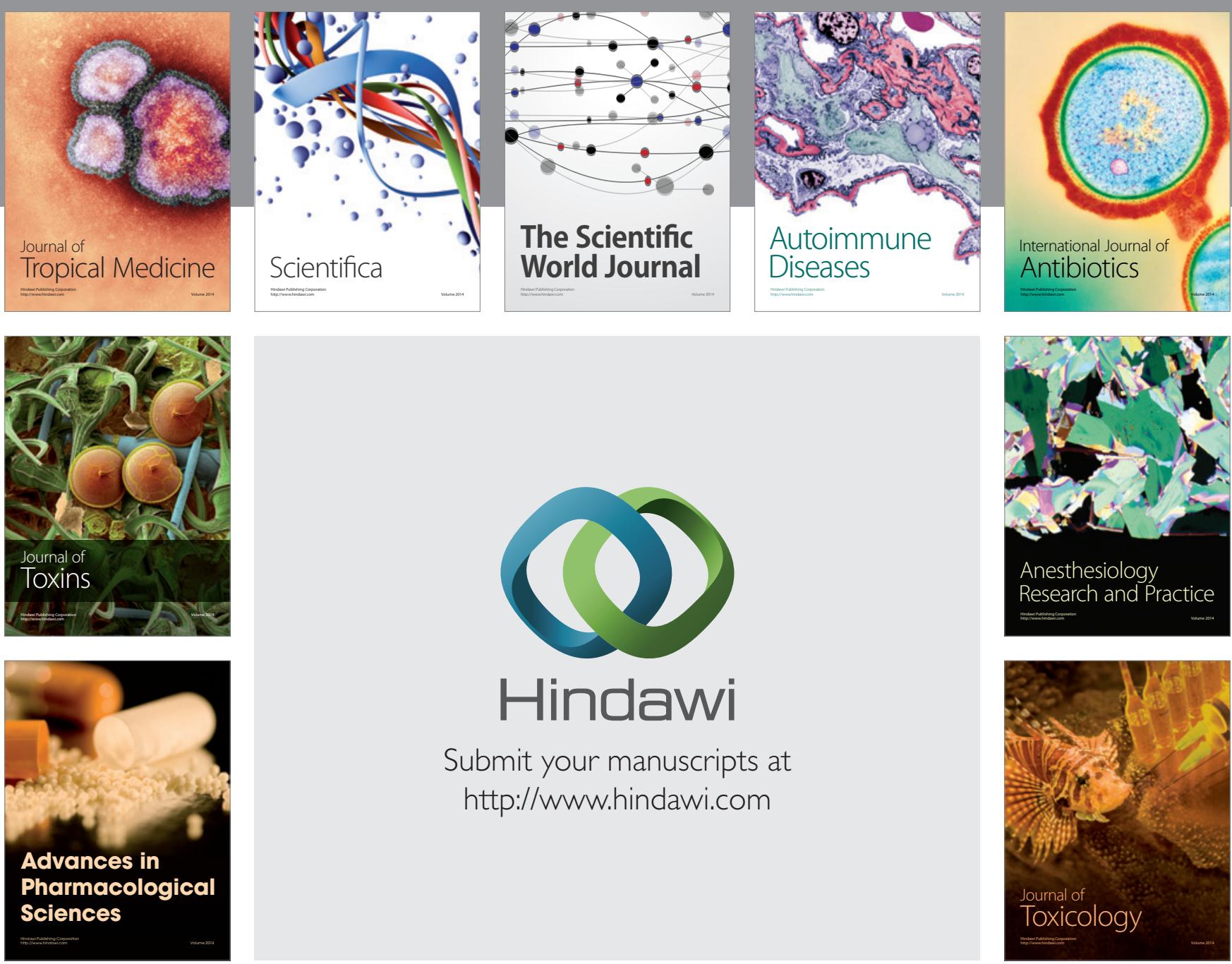

\section{Hindawi}

Submit your manuscripts at

http://www.hindawi.com
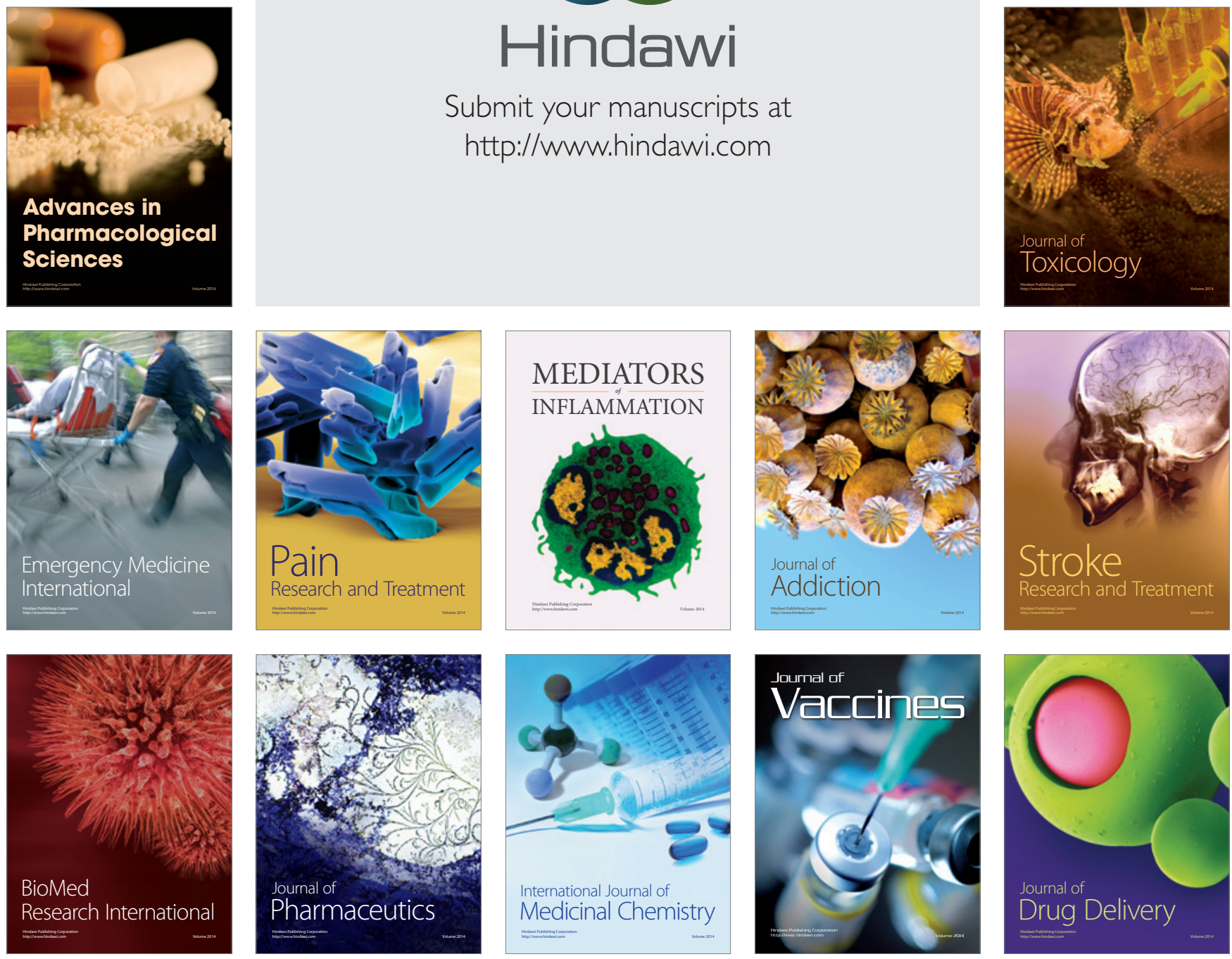